(6) OPEN ACCESS

- Additional material is published online only. To view please visit the journal online (http://dx.doi.org/10.1136/ thoraxjnl-2013-204667)

${ }^{1}$ Sheffield Pulmonary Vascular Disease Unit, Royal Hallamshire Hospital, Sheffield, UK ${ }^{2}$ Academic Department of Respiratory Medicine, Sheffield Teaching Hospitals NHS Foundation Trust, Sheffield, UK ${ }^{3}$ Sheffield Haemophilia and Thrombosis Centre, Royal Hallamshire Hospital, Sheffield, UK

${ }^{4}$ Department of Infection and Immunology, University of Sheffield, Sheffield, UK

\section{Correspondence to} Dr Robin Condliffe, Sheffield Pulmonary Vascular Disease Unit, Royal Hallamshire Hospital, Glossop Road, Sheffield S10 2JF, UK; robin.condliffe@sth.nhs.uk

Received 10 October 2013 Revised 22 November 2013 Accepted 27 November 2013 Published Online First 16 December 2013
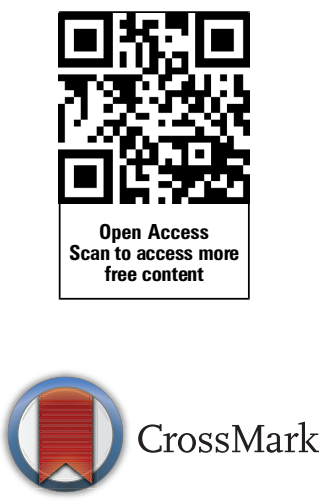

To cite: Condliffe $R$, Elliot CA, Hughes RJ, et al. Thorax 2014;69:174-180.

\title{
Management dilemmas in acute pulmonary embolism
}

\author{
Robin Condliffe, ${ }^{1,2}$ Charlie A Elliot, ${ }^{1,2}$ Rodney J Hughes, ${ }^{2}$ Judith Hurdman, ${ }^{1,2}$ \\ Rhona M Maclean, ${ }^{3}$ Ian Sabroe, ${ }^{1,2,4}$ Joost J van Veen, ${ }^{3}$ David G Kiely, ${ }^{1,2}$
}

ABSTRACT

Background Physicians treating acute pulmonary embolism (PE) are faced with difficult management decisions while specific guidance from recent guidelines may be absent.

Methods Fourteen clinical dilemmas were identified by physicians and haematologists with specific interests in acute and chronic PE. Current evidence was reviewed and a practical approach suggested.

Results Management dilemmas discussed include: submassive PE, PE following recent stroke or surgery, thrombolysis dosing and use in cardiac arrest, surgical or catheter-based therapy, failure to respond to initial thrombolysis, PE in pregnancy, right atrial thrombus, role of caval filter insertion, incidental and sub-segmental $P E_{\text {, }}$ differentiating acute from chronic $P E$, early discharge and novel oral anticoagulants.

Conclusion The suggested approaches are based on a review of the available evidence and guidelines and on our clinical experience. Management in an individual patient requires clinical assessment of risks and benefits and also depends on local availability of therapeutic interventions.

\section{INTRODUCTION}

Several guidelines on acute pulmonary embolism (PE) have been published. ${ }^{1-3}$ Guidance for various scenarios which challenge physicians in the management of acute PE are often not easily accessible in guidelines. Our institution runs an integrated PE service between respiratory and haematology physicians and a large tertiary pulmonary hypertension service. We are not infrequently referred complex acute PE cases from other centres. In this review we discuss the most clinically challenging scenarios.

\section{METHODS}

Eight physicians with an interest in the management of acute and chronic pulmonary embolic disease compiled a list of 14 challenging clinical issues faced in their day-to-day practice. A PubMed search for each dilemma was performed, an initial review and suggested approach drafted followed by round-table discussion to achieve consensus regarding management. In many dilemmas, conclusions based on the available literature, were hampered by patient numbers and reporting bias. Suggested approaches were provided based on consensus.

\section{DEFINITION OF PE SEVERITY}

In the current paper we have adopted the American Heart Association (AHA) classification. ${ }^{3}$ Massive PE is defined as sustained hypotension (systolic blood pressure $<90 \mathrm{~mm} \mathrm{Hg}$ ) for $>15$ min secondary to acute PE or a requirement of inotropes or signs of shock. Submassive PE is defined by evidence of right ventricular (RV) dysfunction and/or evidence of myocardial necrosis. Patients with none of these features are defined as low-risk.

\section{CLINICAL DILEMMAS}

Which patients with submassive PE should I thrombolyse?

The pro-con debate published in this issue of Thorax highlights the controversy regarding systemic thrombolytics in normotensive patients with PE. ${ }^{45}$ Clinical trials have demonstrated more rapid, immediate haemodynamic improvement and clot resolution following thrombolysis, but not clear mortality benefits. ${ }^{67}$ Recent data from a large unselected national registry demonstrated that thrombolysis in normotensive patients with acute PE was associated with increased mortality. ${ }^{8}$ Consideration for thrombolysis therefore requires risk stratification. Validated severity scoring systems, such as the PE Severity Index (PESI, table 1), can identify clinical features at the time of presentation associated with poorer outcome. ${ }^{9}$ European Society of Cardiology (ESC) guidelines suggest assessing for RV dysfunction (using echocardiography, CT or B-type natriuretic peptide) or ischaemia (troponin) to aid risk stratification. ${ }^{1}$ The presence of lower limb deep venous thrombosis (DVT) has also been associated with poorer survival. ${ }^{10}$ By combining these factors it is possible to identify a higher risk population with 30 -day mortality $>20 \%$ (table 2 ). ${ }^{11}$ A meta-analysis of randomised controlled trials (RCTs) of thrombolysis in massive and submassive PE published prior to 2004 reported a risk of major

Table 1 PE severity index (adapted from Aujesky et $a l^{9}$ )

\begin{tabular}{ll}
\hline Predictor & Points \\
\hline Demographic & \\
Age, per year & Age, in years \\
Men & +10 \\
Comorbidities & \\
$\quad$ Cancer & +30 \\
Heart failure & +10 \\
Chronic lung disease & +10 \\
Clinical findings & \\
Pulse $\geq 110$ & +20 \\
Systolic blood pressure $<100$ mm Hg & +30 \\
Respiratory rate $\geq 30$ & +20 \\
Temperature $<36$ & +20 \\
Altered mental status & +60 \\
Saturations $<90 \%$ & +20 \\
\hline Total points: $\leq 65$ class I (very low risk), $66-85$ class II (low risk), \\
$86-105$ class III (intermediate risk), 106-125 class IV (high risk), \\
$\geq 126$ class V (very high risk).
\end{tabular}


Table 2 Clinical, laboratory and echo parameters predicting 30-day PE-related mortality in normotensive patients (adapted from Jimenez et $a l^{11}$ )

\begin{tabular}{lc}
\hline & PPV (\%) \\
\hline Trop & 10.5 \\
RVD & 11.7 \\
DVT & 9.6 \\
Trop and RVD & 15.2 \\
Trop and DVT & 17.1 \\
RVD and DVT & 19.6 \\
Trop, RVD and DVT & 20.8 \\
High-risk PESI, Trop and RVD & 20.7 \\
High-risk PESI, Trop and DVT & 24.4 \\
High-risk PESI, RVD and DVT & 25.0 \\
\hline DVT, deep venous thrombosis on compression ultrasound; PESI, PE severity index; \\
PPV, positive predictive value; RVD, right ventricular dysfunction on echocardiography; \\
Trop, elevated troponin I.
\end{tabular}

bleeding of $9.1 \%$ and intracranial haemorrhage $(\mathrm{ICH})$ of $0.5 \%$ while a recent large RCT of tenecteplase in submassive PE (PEITHO) observed rates of major bleeding of $6.3 \%$ and ICH of $2 \%$ (compared with $1.5 \%$ and $0.2 \%$ respectively for heparin alone). ${ }^{12}$ Interestingly, bleeding risk was lower and mortality benefit higher in patients $<75$ years.

Suggested approach: In submassive PE we would not routinely administer thrombolysis. PESI score and the presence or absence of single or multiple poor prognostic factors should be balanced against factors associated with increased risk of bleeding (including age) in identifying suitable candidates for thrombolysis.

\section{What is the risk of thrombolysis in a patient with recent surgery, previous stroke or intracranial space-occupying lesion? Thrombolysis after recent surgery}

We identified 25 reports, including 64 patients, thrombolysed (the majority for PE) following major recent surgery ${ }^{13-37}$ (see online supplementary table S3). Major bleeding occurred in $>50 \%$ of patients receiving thrombolysis within 1 week of surgery and in $20 \%$ of patients thrombolysed 1-2 weeks postoperatively. American College of Chest Physicians (ACCP) guidelines suggest that recent surgery (excluding recent brain or spinal surgery or trauma) is a relative contraindication and that the bleeding risk reduces significantly 2 weeks after surgery.

\section{Thrombolysis in the presence of intracranial} space-occupying lesions

A review of 12 patients with intracranial neoplasms thrombolysed for various indications identified ICH in a single patient $(8.3 \%) .^{38}$ Guillan $e^{2} a l^{39}$ identified five cases (five meningiomas, one cholesteatoma and one paranasal tumour) receiving systemic thrombolysis for stroke without complications. The risk of ICH is dependent on tumour type and localisation. A clinicopathological study showed the risk of microscopic and macroscopic spontaneous bleeding to be $50 \%$ in metastatic melanoma and ranging from $29.2 \%$ in oligodendroglioma to $2.8 \%$ in meningioma. ${ }^{40}$

\section{Thrombolysis after recent ischaemic stroke}

Previous ischaemic stroke within 3 or 6 months is a contraindication to thrombolysis in ACCP and ESC guidelines. ${ }^{12}$ A study involving 145 patients with a stroke within 3 months who received thrombolysis for a further stroke did not show an increase in $\mathrm{ICH}$ rate. $^{41}$

Suggested approach: In patients with a massive PE within 1 week of surgery we would favour mechanical treatment if available. Within 1-2 weeks following surgery, thrombolysis may be an acceptable risk depending on the nature of the surgery. In our opinion previous ischaemic stroke is not an absolute contraindication to thrombolysis but there are no data to guide an acceptable timescale since the stroke. Selected intracranial spaceoccupying lesions, for example meningiomas, would not influence our decision to thrombolyse.

A patient with an acute cerebral infarct is found to have an acute PE: what should I do regards anticoagulation?

Patients rarely present with a stroke and PE simultaneously due to paradoxical embolisation across a patent foramen ovale (PFO). ${ }^{42}{ }^{43}$ More frequently (1-10\% of cases) patients may develop an acute PE following a stroke. ${ }^{44} \mathrm{PE}$ is the most common cause of death $2-4$ weeks post stroke. ${ }^{44}$ In the absence of anticoagulation, the majority of haemorrhagic transformation involves petechial bleeds with low risk of mass effect. ${ }^{45-47}$ However, low and intermediate dose heparin early after stroke presentation is associated with an increased rate of haemorrhagic transformation. ${ }^{48-50}$ Stroke guidelines advise delaying anticoagulation for 2 weeks post ischaemic stroke in patients with atrial fibrillation but give discordant advice regarding anticoagulation for coexisting PE. UK stroke guidance suggests anticoagulation for proximal DVT or PE while AHA guidelines do not recommend initial anticoagulation in patients with moderate to severe stroke. ${ }^{5152}$

Suggested approach: The risk-benefit ratio for individual patients should be assessed; however, our general approach is to anticoagulate all patients with a cerebral infarct and PE. In patients with PE with a primary haemorrhagic stroke or recent significant haemorrhagic transformation we would consider inferior vena cava (IVC) filter insertion and delayed anticoagulation.

\section{What is the optimal type and dose of thrombolytic agent and what should I do if a patient is already on low molecular weight heparin?}

Thrombolytic agents for PE should be administered peripherally. $^{2}$ Several thrombolytic agents have been studied: urokinase, streptokinase and recombinant tissue plasminogen activators (alteplase, reteplase, desmoteplase and tenecteplase). ${ }^{2}$ Alteplase is the most widely used thrombolytic agent for PE; recommended dosing in patients $\geq 65 \mathrm{~kg}$ is a loading bolus of $10 \mathrm{mg}$ over $1-2 \mathrm{~min}$ followed by $90 \mathrm{mg}$ infused over $2 \mathrm{~h}^{53} \mathrm{In}$ patients $<65 \mathrm{~kg}$ the total dose administered is $1.5 \mathrm{mg} / \mathrm{kg}$; for example a patient weighing $60 \mathrm{~kg}$ should receive a $10 \mathrm{mg}$ loading bolus followed by $80 \mathrm{mg}$ over $2 \mathrm{~h}$. In patients already receiving intravenous heparin we stop the infusion prior to administration of alteplase, check activated partial thromboplastin time (APTT) $2 \mathrm{~h}$ following completion of administration and restart heparin when the APTT ratio is $<2 \times$ the upper limit of normal. If there is good clinical response to thrombolysis we would convert to low molecular weight heparin (LMWH) $24 \mathrm{~h}$ following thrombolysis. If therapeutic LMWH had been administered prior to thrombolysis we would usually start heparin infusion as above but delay commencement to $18 \mathrm{~h}$ following the last dose of LMWH if once-daily dosing and 8-10 h if twice-daily dosing had been used. Two RCTs have investigated the efficacy and side effects of half-dose alteplase in predominantly submassive PE. ${ }^{54} 55$ Superior efficacy with no increase in bleeding risk was observed when compared with anticoagulation alone, ${ }^{54}$ and equal efficacy with less haemorrhage was seen when compared with standard-dose anticoagulation. ${ }^{55}$ 
Suggested approach: If thrombolysis is indicated for PE we would administer a $10 \mathrm{mg}$ bolus of alteplase followed by a further $90 \mathrm{mg}$ over $2 \mathrm{~h}$ (up to a maximum of $1.5 \mathrm{mg} / \mathrm{kg}$ ). If thrombolysis is indicated but there is a high risk of haemorrhage we would consider using a half-dose regimen.

\section{Which patients in an arrest or peri-arrest situation should I consider thrombolysing in the absence of definitive radiological evidence of $\mathrm{PE}$ ?}

If $\mathrm{PE}$ is suspected clinically in an acutely deteriorating patient who is too unwell for CT pulmonary angiogram (CTPA) then echocardiography may identify signs of acute right heart strain suggestive of acute PE. ${ }^{56} 57$ Thrombolysis can increase the return of spontaneous circulation and survival to discharge in patients with known or suspected PE who have cardiac arrest. ${ }^{58-60}$ British Thoracic Society guidelines suggest a bolus dose of $50 \mathrm{mg}$ alteplase in the peri-arrest or arrest situation. ${ }^{61}$ Patients who have arrested and then regained circulation may also be suitable for emergency pulmonary embolectomy. ${ }^{62}$ Patients in whom the cause of arrest is unclear should not receive thrombolysis during cardiopulmonary resuscitation. ${ }^{2} \mathrm{~A}$ recent large RCT demonstrated that thrombolysis in out-of-hospital cardiac arrest when the cause of arrest is undifferentiated is not associated with significant mortality benefit. ${ }^{63}$

Suggested approach: Thrombolysis should be administered in the peri-arrest or arrest situation when PE is either known or suspected.

\section{I feel it is too unsafe to perform thrombolysis: what are the surgical and non-surgical alternatives?}

If thrombolytic therapy is contraindicated and a patient has significant accessible PE and persisting haemodynamic compromise then embolectomy, performed by an open surgical or catheterbased approach, should be considered. ${ }^{1}$ Older case series observed mortality rates for surgical embolectomy of $>20 \% ;^{3}$ however an intraoperative mortality of $6 \%$ was reported in 47 consecutive patients. ${ }^{64}$ Catheter-directed therapies include mechanical disruption of thrombi by catheter, ultrasound or pressurised saline injection. ${ }^{65}$ Suction may be used to perform thrombectomy or aspirate fragments of macerated emboli following other techniques. A recent meta-analysis observed $87 \%$ clinical success. ${ }^{66}$ Local intra-clot thrombolytic was used in $67 \%$ of cases and was associated with superior clinical success, postulated due to increased thrombus surface area exposed to thrombolysis after fragmentation. Major complications of catheter-directed therapy including pulmonary artery rupture and massive haemoptysis were seen in $2.4 \%$ of cases while haemodynamic deterioration due to fragmented emboli was unpredictable. ${ }^{66}$ Although the incidence of major bleeding in the meta-analysis was low (18 non-cerebral haemorrhages requiring transfusion and 1 intra-cerebral haemorrhage reported in 594 patients $^{66}$ ) the absolute risk of bleeding related to intraclot thrombolysis in an individual patient with a contraindication to systemic thrombolysis is not clear. There are few data comparing thrombolysis, surgical embolectomy and catheterbased intervention as primary treatment for massive PE. Current guidelines restrict surgical embolectomy to situations when thrombolysis has failed or is contraindicated. ${ }^{1}$ Although there is increasing interest in the expansion of surgical embolectomy to the initial management of massive PE, randomised trial data are required. ${ }^{62} 6467-70$

Suggested approach: No comparative data exist to guide primary management of massive PE in the presence of a strong contraindication to systemic thrombolysis. Management is dependent on local availability of cardiothoracic surgery and catheter-based therapy.

\section{A patient with a recent acute PE fails to respond to initial therapy: what should I do?}

If a patient with acute PE fails to respond to initial anticoagulation, with worsening cardiovascular instability and/or respiratory failure, then thrombolysis should be considered. In the MAPPET-3 study of submassive PE, delayed thrombolysis was performed in $23 \%$ of patients treated initially with heparin, with no difference in mortality compared with patients receiving up-front thrombolysis. ${ }^{6}$ Although reperfusion is greater the earlier thrombolysis is given, benefit may be observed when administered up to 14 days from symptom onset. ${ }^{71}$ Failure to improve following thrombolysis may be related to persistent thrombus, complications such as lung infarction or infection or existence of chronic clot. Reassessment with additional imaging may therefore be required. In the presence of persistent clot, repeat thrombolysis or mechanical therapy may be considered. A single centre retrospective study of treatment in failed thrombolysis demonstrated that mortality in patients receiving repeat thrombolysis was 38\% compared with $7 \%$ in patients undergoing embolectomy, although bias in management approach cannot be excluded. ${ }^{72}$ Supportive therapy for lung infarction may include ventilatory support, treatment of superadded infection and inotropic support. If underlying chronic thromboembolic disease is suspected, referral for pulmonary endartectomy and the use of bridging pulmonary vasodilator therapy should be considered. The role of pulmonary vasodilators in purely acute disease has also been assessed. ${ }^{73}$ Inhaled nitric oxide may improve gas exchange in acute PE. ${ }^{74} 75$ Limited data suggest possible benefit from nebulised iloprost ${ }^{76} 77$ while a small RCT failed to demonstrate benefit from intravenous eposprostenol. ${ }^{78}$ There are limited reports of benefit from sildenafil in animal models and humans with acute PE. ${ }^{79}$

Suggested approach: Thrombolysis should be considered when a patient initially treated with anticoagulation alone develops worsening cardiovascular instability or respiratory failure. Failure to improve following thrombolysis should trigger reassessment for residual clot or complication of PE. Surgical embolectomy is preferable to re-thrombolysis for persistent obstructing acute PE.

\section{How should I manage a pregnant patient with significant PE?}

In non-massive PE, therapeutic LMWH has been shown to be safe and effective at preventing recurrent $\mathrm{PE}$ and does not cross the placenta. ${ }^{80}$ Warfarin administration is teratogenic in the first trimester but is also associated with neural abnormalities during any trimester and UK obstetric guidelines advise against its use during pregnancy. ${ }^{81} 82$ If $\mathrm{PE}$ is within a month of the expected date of delivery then a retrievable IVC filter should be inserted. A recent review identified 189 pregnant patients receiving thrombolysis for venous thromboembolism (VTE); major bleeding occurred in $2.6 \%$ with no maternal mortality. ${ }^{83}$ The peripartum period poses a challenge with greater risk of haemorrhage associated with thrombolysis. The use of mechanical disruption, lower-dose catheter-directed thrombolysis and surgical embolectomy has been described and is dependent on local availability. ${ }^{30} 8485$

Suggested approach: Therapeutic LMWH is the anticoagulant of choice in pregnancy. Systemic thrombolysis should be administered for massive PE in pregnancy; however if bleeding risk is 
high (eg, in the peripartum period) then surgical or mechanical methods are suggested, depending on local availability.

\section{An echo demonstrates thrombus in the right atrium: what is the optimal management?}

Right atrial thrombus occurs in $4-8 \%$ of patients with acute PE. ${ }^{86-90}$ Two main types of thrombus have been described: type A has high early mortality and consists of long, thin, worm-like mobile thrombi associated with clinically severe PE. ${ }^{91}$ Low cardiac output, higher pulmonary arterial pressure and more severe tricuspid regurgitation may slow transit of clot from peripheral veins to the pulmonary vasculature. ${ }^{90}$ Type B consists of immobile, non-specific thrombi with absence of associated PE in $60 \%$ of cases and low early mortality. A small proportion of thrombi are intermediate in character (type C), being mobile but not worm-like in shape, and have the potential to obstruct right atrial or ventricular outflow. ${ }^{91-93}$ CTPA is highly effective at identifying type A thrombi with a sensitivity of $100 \%$, although false positives may be observed in patients with non-dilated right ventricles due to incomplete contrast filling. ${ }^{89}$ The optimal management of patients with right atrial thrombus is unclear. Two-week mortality in 42 patients treated with heparin, thrombolysis or surgical embolectomy was equally poor (20-25\%). ${ }^{86}$ A systematic review of 177 cases observed lower mortality in patients receiving thrombolysis (11\%) compared with anticoagulation (29\%) and surgery $(24 \%) .{ }^{94}$ In a series of 16 consecutively thrombolysed patients, right atrial thrombus disappeared in all patients within $24 \mathrm{~h}$ with 30 -day survival of $100 \% .{ }^{90}$ In a minority of patients thrombus may straddle a PFO leading to additional risk of systemic embolisation. A literature review of 88 such patients demonstrated similar mortality $(14 \%)$ but higher incidence of stroke in patients treated with anticoagulation rather than surgical embolectomy. ${ }^{95}$ Patients treated with thrombolysis had a much higher mortality (36\%), although they had more haemodynamic compromise. AHA guidelines therefore recommend surgical embolectomy as the optimal treatment in this group.

Suggested approach: Thrombolysis is suggested for type A thrombus while type B thrombus may be treated with anticoagulation alone. Surgical embolectomy is suggested for thrombus straddling a PFO; if this is not available then anticoagulation alone is a reasonable approach unless thrombolysis is indicated due to the severity of the underlying PE. Surgical embolectomy is suggested for type $\mathrm{C}$ thrombus if the thrombus is extremely large and associated with risk of right atrial or ventricular outflow tract obstruction should it dislodge.

\section{Which patients with acute PE may benefit from an IVC filter?}

Retrievable IVC filter insertion in acute PE should be performed if anticoagulation is contraindicated or temporary cessation of anticoagulation within 1 month is envisaged. An RCT of IVC filter insertion involving 400 patients with proximal DVT receiving anticoagulation demonstrated a reduction in subsequent PE, counterbalanced by an increase in recurrent DVT with no effect on mortality. ${ }^{96} 97$ ACCP guidelines recommend against IVC filter insertion in patients with $\mathrm{PE}$ receiving anticoagulation, although they recognise that there is uncertainty regarding the risk and benefits in patients with hypotension. ${ }^{2}$ Retrospective analysis of data collected by the International Cooperative PE Registry found IVC filter insertion to be associated with a reduced 90-day mortality in the setting of massive PE, although only $10 \%$ of patients received IVC filters and two-thirds of patients did not receive thrombolysis. ${ }^{98}$ A large RCT of retrievable IVC filter insertion in patients with PE and associated DVT (PREPIC-2) has recently been presented in abstract form. ${ }^{99}$ No effect on recurrent PE, complications or mortality was observed.

Suggested approach: We generally limit IVC filter use in acute PTE to the small number of patients in whom anticoagulation is contraindicated. Routine placement of IVC filters in submassive $\mathrm{PE}$ and proximal DVT is not supported by current evidence. If possible we use retrievable filters, which should ideally be removed within the recommended time scale.

\section{How can I differentiate between acute and chronic PE?}

It is not infrequent to see patients with significant proximal chronic thromboembolic disease who have erroneously been thrombolysed. Several factors may suggest chronic rather than acute PE. Long duration of symptoms, a previous VTE, features of pulmonary hypertension on examination in the absence of systemic hypotension and or tachycardia and bilateral bruits due to stenoses (appreciated during breath hold on auscultation) favour a chronic process. ${ }^{100}$ Electrocardiographic and echocardiographic changes indicating longstanding increased RV afterload include a dominant $\mathrm{R}$ wave in $\mathrm{V} 1$ with absence of tachycardia and a systolic pulmonary artery pressure $>60 \mathrm{~mm} \mathrm{Hg}$ on echocardiography (the RV cannot acutely generate a higher pressure). ${ }^{101}$ McConnell's sign (RV free wall hypokinesis with preserved $\mathrm{RV}$ apical contraction) and the '60/60' sign (pulmonary acceleration time below $60 \mathrm{~ms}$ with a tricuspid gradient of $30-60 \mathrm{~mm} \mathrm{Hg}$ on echocardiography) suggest acute rather than chronic PE. ${ }^{56} 57$ An increased RV-LV ratio may be present in acute and chronic thromboembolic disease but the presence of RV hypertrophy and large bronchial arteries are suggestive of chronic disease. ${ }^{102}$ Within the pulmonary arteries, mural calcified thrombus forming an obtuse angle with the vessel wall, completely stenosed and narrowed segmental vessels and signs of recanalisation with contrast flowing either side of 'webs' of organised thrombi are suggestive of chronic disease. ${ }^{103}$ Within the parenchyma, peripheral wedgeshaped infarcts may be present in acute PE while a mosaic perfusion pattern with reduction in pulmonary arterial size in low attenuation areas of the lung suggests chronic disease.

Suggested approach: A chronic history, markedly elevated systolic pulmonary arterial pressures, RV and bronchial artery hypertrophy, thrombus calcification, webs and a mosaic perfusion pattern should raise suspicion of chronic rather than acute PE.

\section{In which patients should I consider early discharge?}

Clinical severity scoring systems have more clearly identified patients at low risk of complications from acute PE who may not require hospitalisation. PESI is the most widely validated scoring system and has been utilised in prospective randomised management studies to demonstrate the safety of such an approach, which may be appropriate in up to $40 \%$ of patients. ${ }^{104} 105106$ Outpatient management of PE generally requires LMWH administration during oral anticoagulant initiation, ${ }^{105}$ although the introduction of oral factor $\mathrm{Xa}$ inhibitors provides the possibility of a more convenient ambulatory treatment for patients. ${ }^{107} 108$ Safe early discharge of patients is dependent on a robust multidisciplinary approach involving rapid imaging, accurate assessment and adequate support and follow-up mechanisms for the discharged patient. Admission of patients at very low or low risk may still be advisable due to patient concern or ongoing pain. Repeat PESI scoring after $48 \mathrm{~h}$ in patients initially assessed as unsuitable for discharge may reclassify them as appropriate for outpatient anticoagulation. ${ }^{109}$ 
Suggested approach: Patients with a very low or low PESI score may be offered early discharge and outpatient anticoagulation but a robust system of support and follow-up is mandatory.

\section{What is the role of the newer oral agents in the management of acute PE?}

At the time of writing, rivaroxaban, a direct Xa inhibitor, is the only new oral anticoagulant (NOAC) licensed and approved for the treatment and secondary prevention of DVT and PE in the UK. ${ }^{108}$ Other NOACs (dabigatran: a direct thrombin inhibitor; and apixaban and edoxaban: direct Xa inhibitors), however, have also been shown to be non-inferior to conventional anticoagulant therapy with favourable safety profiles in the treatment of patients with PE. In the dabigatran (RE-COVER) ${ }^{110}$ and edoxaban (HOKUSAI) ${ }^{111}$ studies, all patients initially received heparin for 10 and 7 days. The rivaroxaban (EINSTEIN-PE) and apixaban (AMPLIFY) studies excluded patients who had had more than $48 \mathrm{~h}$ of heparin, thus these therapies introduce the option of managing patients without parenteral anticoagulation. ${ }^{112} 113$ Patients with active malignancy were excluded from these studies (LMWH remains the standard of care for these patients), and NOACs should not be used in pregnant or lactating women, or in patients with significant renal impairment. Importantly, no regular monitoring is required.

Suggested approach: Other NOACs may also become licensed in the future but currently rivaroxaban can be considered an option for the acute management of haemodynamically stable patients with PE within its product license.

\section{What should I do about an incidental or isolated subsegmental PE?}

Demonstration of unsuspected PE occurs in up to 5\% of thoracic CT scans performed for non-PE indications, the majority in the context of malignancy. ${ }^{114-118}$ In malignancy, most incidental PEs are lobar or segmental in distribution while VTE recurrence rate, mortality and complications are not significantly different between incidental and symptomatic PE. ${ }^{119}$ The ACCP guidelines suggest asymptomatic PE should be treated as symptomatic PE. $^{2}$ Isolated subsegmental PEs are demonstrated in $1-5 \%$ of CTPAs performed for suspected PE and 10\% of CTPAs with demonstrable PE. ${ }^{114}{ }^{120-122}$ Optimal management of these patients is unclear. Pooled data from 105 patients with predominantly isolated subsegmental PE with no evidence of DVT on serial imaging who did not receive anticoagulation found no patients with recurrent PE after 3 months. ${ }^{120}$ The authors therefore suggested that the risk of haemorrhage may outweigh the benefit of anticoagulation in isolated PE, assuming negative serial compression ultrasound of lower limb veins. ${ }^{120}$ This approach has been challenged by a large prospective study which found similar risk factors and recurrence rates in patients with symptomatic subsegmental versus more proximal PE, although it is unclear how many patients had a single subsegmental PE. ${ }^{123}$

Suggested approach: Incidental and isolated subsegmental PE should generally be managed in the same manner as symptomatic and non-subsegmental PE.

\section{CONCLUSION}

The suggested approaches are based on a review of the available evidence and guidelines and on our clinical experience. For many of the dilemmas the evidence base is not substantial and is potentially hampered by reporting bias. Management in an individual patient will require clinical assessment of risks and benefits and will also depend on local availability of therapeutic interventions.
Contributors RC and DGK conceived the article. All authors wrote sections and reviewed the whole of the manuscript.

Competing interests $R C$ and DGK have received funding for conference attendance and honoraria for advisory boards and lecturing from Bayer and GSK, funding for conference attendance from Pfizer and their unit has received an unrestricted educational grant to part-fund a radiographer from Bayer. CAE has received funding for conference attendance and honoraria for lecturing from Bayer, and for conference attendance and honoraria for advisory boards and lecturing from GSK. JH has received funding for conference attendance and honoraria for advisory boards from Bayer. RJH has received honoraria for advisory boards and lecturing from Bayer, Boehringer Ingelheim and Sanofi Aventis. RMM has received funding to attend meetings from Daiichi-Sankyo, Bayer and Boehringer Ingelheim, and received honoraria for advisory board meetings and/or delivering educational sessions for Bayer, Daiichi-Sankyo and Pfizer. IS receives an annual unrestricted educational grant from GSK to support a clinical meeting. JVV has received funding to attend meetings from Boehringer Ingelheim and honoraria for advisory boards from Bayer.

Provenance and peer review Not commissioned; externally peer reviewed.

Open Access This is an Open Access article distributed in accordance with the Creative Commons Attribution Non Commercial (CC BY-NC 3.0) license, which permits others to distribute, remix, adapt, build upon this work non-commercially, and license their derivative works on different terms, provided the original work is properly cited and the use is non-commercial. See: http://creativecommons.org/ licenses/by-nc/3.0/

\section{REFERENCES}

1 Torbicki A, Perrier A, Konstantinides $S$, et al. Guidelines on the diagnosis and management of acute pulmonary embolism: the Task Force for the Diagnosis and Management of Acute Pulmonary Embolism of the European Society of Cardiology (ESC). Eur Heart J 2008;29:2276-315.

2 Kearon C, Akl EA, Comerota AJ, et al. Antithrombotic therapy for VTE disease: Antithrombotic Therapy and Prevention of Thrombosis, 9th ed: American College of Chest Physicians Evidence-Based Clinical Practice Guidelines. Chest 2012;141: e419S-94S.

3 Jaff MR, McMurtry MS, Archer SL, et al. Management of massive and submassive pulmonary embolism, iliofemoral deep vein thrombosis, and chronic thromboembolic pulmonary hypertension: a scientific statement from the American Heart Association. Circulation 2011;123:1788-830.

4 Howard L. Thrombolytic therapy for submassive PE? PRO viewpoint. Thorax 2014;69:103-5.

5 Simpson J. Thrombolytic therapy for submassive PE? CON viewpoint. Thorax 2014;69:105-7.

6 Konstantinides S, Geibel A, Heusel G, et al. Heparin plus alteplase compared with heparin alone in patients with submassive pulmonary embolism. N Engl J Med 2002;347:1143-50.

7 Fasullo S, Scalzo S, Maringhini G, et al. Six-month echocardiographic study in patients with submassive pulmonary embolism and right ventricle dysfunction: comparison of thrombolysis with heparin. Am J Med Sci 2011;341:33-9.

8 Riera-Mestre A, Jimenez D, Muriel A, et al. Thrombolytic therapy and outcome of patients with an acute symptomatic pulmonary embolism. J Thromb Haemost 2012;10:751-9.

9 Aujesky D, Obrosky DS, Stone RA, et al. Derivation and validation of a prognostic model for pulmonary embolism. Am J Respir Crit Care Med 2005;172:1041-6.

10 Jimenez D, Aujesky D, Diaz G, et al. Prognostic significance of deep vein thrombosis in patients presenting with acute symptomatic pulmonary embolism. Am J Respir Crit Care Med 2010;181:983-91.

11 Jimenez D, Aujesky D, Moores L, et al. Combinations of prognostic tools for identification of high-risk normotensive patients with acute symptomatic pulmonary embolism. Thorax 2011;66:75-81.

12 Konstantinides S; on behalf of the PEITHO investigators. Fibrinolysis for normotensive patients with acute submassive pulmonary embolism. http://clinicaltrialresults.org/Slides/ACC\%202013/Konstantinides_PEITHO_ACC\% 202013.pdf (accessed Nov 2013).

13 Meretoja A, Putaala J, Tatlisumak T, et al. Off-label thrombolysis is not associated with poor outcome in patients with stroke. Stroke 2010;41:1450-8.

14 Eckardt J, Licht PB. Successful thrombolysis of major pulmonary embolism 5 days after lobectomy. Interact Cardiovasc Thorac Surg 2012;14:660-1.

15 Kameyama K, Huang CL, Liu D, et al. Pulmonary embolism after lung resection: diagnosis and treatment. Ann Thorac Surg 2003;76:599-601.

16 Sakuragi T, Sakao Y, Furukawa K, et al. Successful management of acute pulmonary embolism after surgery for lung cancer. Eur J Cardiothorac Surg 2003;24:580-7.

17 Zhang $\mathrm{K}$, Zeng $\mathrm{X}$, Zhu C, et al. Successful thrombolysis in postoperative patients with acute massive pulmonary embolism. Heart Lung Circ 2012 Published Online First 12 October 2012 doi:10.1016/j.hlc.2012.08.055

18 Girard P, Baldeyrou P, Le Guillou JL, et al. Thrombolysis for life-threatening pulmonary embolism 2 days after lung resection. Am Rev Respir Dis 1993;147:1595-7. 
19 Martin SL, Tellez MG. Utilization of alteplase in trauma victim with an open abdomen. J Emerg Trauma Shock 2011;4:427-9.

20 Sayeed RA, Nashef SA. Successful thrombolysis for massive pulmonary embolism after pulmonary resection. Ann Thorac Surg 1999;67:1785-7.

21 Scheffler M, Menges T, Zorb C, et al. Successful thrombolysis of a massive pulmonary embolism following pneumonectomy. Anaesthesist 2008;57:355-8.

22 Ezzet KA. Reversal of acute ischemic stroke after THA using tissue plasminogen activator. Orthopedics 2013;36:e676-8.

23 Klaus S, Bahlmann L, Mierisch C, et al. Early postoperative thrombolytic therapy after laparotomy. Resuscitation 2001;50:353-5.

24 Ruiz-Bailen M, Narbona-Carvo B, Ramos-Cuadra JA, et al. Systemic thrombolysis for prosthetic valve thrombosis in the immediate postoperative period of major abdominal surgery. J Thorac Cardiovasc Surg 2007;133:801-3.

25 Severi $P$, Lo Pinto $G$, Poggio $R$, et al. Urokinase thrombolytic therapy of pulmonary embolism in neurosurgically treated patients. Surg Neurol 1994;42:469-70.

26 Weiner RA, Daskalakis M, Theodoridou S, et al. Systemic thrombolysis for acute massive pulmonary embolism in the immediate postoperative period after bariatric surgery. Surg Obes Relat Dis 2009:5:271-4.

27 Ayad S, Tetzlaff JE. Massive pulmonary embolism in a patient undergoing Cesarean delivery. J Clin Anesth 2012;24:582-5.

28 Mick SL. Thrombolytic therapy following rhytidectomy and blepharoplasty. Plast Reconstr Surg 2004;113:19e-24e.

29 Seifert $\mathrm{CL}$, Sprenger T, Mucke T, et al. Systemic thrombolysis in ischemic stroke after recent oral surgery and management of oral cavity bleeding. Ann Emerg Med 2011:57:517-19.

30 Wenk M, Popping DM, Hillyard S, et al. Intraoperative thrombolysis in a patient with cardiopulmonary arrest undergoing caesarean delivery. Anaesth Intensive Care 2011;39:671-4.

31 Cable DG, Cherry KJ. Systemic thrombolytic therapy after recent abdominal aortic aneurysm repair: an absolute contraindication? Mayo Clin Proc 2003;78:99-102.

32 Gough-Palmer A, Harman F. Bilateral intraorbital haematomata following thrombolysis for pulmonary embolism. Eye 2009;23:987-9.

33 Leong JK. Orbital haemorrhage complication following postoperative thrombolysis. Br J Ophthalmol 2003;87:655-6.

34 Lopez-Yunez AM, Bruno A, Williams LS, et al. Protocol violations in community-based rTPA stroke treatment are associated with symptomatic intracerebral hemorrhage. Stroke 2001;32:12-16.

35 Wilson AT, Woodmansey PA, Channer KS. Thrombolysis for postoperative pulmonary embolism. Lancet 1992;340:492.

36 Schmidt $\mathrm{KI}$, Fries $\mathrm{P}$, Feldner SK, et al. Successful thrombolysis after pulmonary endarterectomy. Ann Thorac Surg 2010;90:2051-3.

37 Wright HJ, Campbell R, Ellis $\mathrm{S}$, et al. Thrombolysis for postoperative pulmonary embolism: limiting the risk of haemorrhage. Thorax 2010;66:452.

38 Etgen T, Steinich I, Gsottschneider L. Thrombolysis for ischemic stroke in patients with brain tumors. J Stroke Cerebrovasc Dis 2013 Published Online First 11 June 2013 doi:10.1016/j.jstrokecerebrovasdis.2013.05.004

39 Guillan M, Alonso-Canovas A, Garcia-Caldentey J, et al. Off-label intravenous thrombolysis in acute stroke. Eur J Neurol 2012;19:390-4.

40 Kondziolka $D$, Bernstein $M$, Resch $L$, et al. Significance of hemorrhage into brain tumors: clinicopathological study. J Neurosurg 1987;67:852-7.

41 Karlinski M, Kobayashi A, Mikulik R, et al. Intravenous alteplase in ischemic stroke patients not fully adhering to the current drug license in Central and Eastern Europe. Int J Stroke 2012;7:615-22.

42 Iskander A, Nayak A, Chauhan MS. Submassive pulmonary embolism and paradoxical embolic stroke treated with percutaneous rheolytic thrombectomy and closure of the patent foramen ovale. Catheter Cardiovasc Interv 2005;64:356-60.

43 Pavesi PC, Pedone C, Crisci $M$, et al. Concomitant submassive pulmonary embolism and paradoxical embolic stroke after a long flight: which is the optimal treatment? J Cardiovasc Med 2008;9:1070-3.

44 Kelly J, Rudd A, Lewis $\mathrm{R}$, et al. Venous thromboembolism after acute stroke. Stroke 2001;32:262-7.

45 Mudd PD, James MA. Anticoagulation for atrial fibrillation: should warfarin be temporarily stopped or continued after acute cardioembolic stroke? Age Ageing 2010;39:670-3.

46 Hallevi H, Albright KC, Martin-Schild S, et al. The complications of cardioembolic stroke: lessons from the VISTA database. Cerebrovasc Dis 2008:26:38-40.

47 Berger $C$, Fiorelli $M$, Steiner $T$, et al. Hemorrhagic transformation of ischemic brain tissue: asymptomatic or symptomatic? Stroke 2001;32:1330-5.

48 International Stroke Trial Collaborative Group. The International Stroke Trial (IST): a randomised trial of aspirin, subcutaneous heparin, both, or neither among 19435 patients with acute ischaemic stroke. Lancet 1997;349:1569-81.

49 Camerlingo M, Salvi P, Belloni G, et al. Intravenous heparin started within the first 3 hours after onset of symptoms as a treatment for acute nonlacunar hemispheric cerebral infarctions. Stroke 2005;36:2415-20.

50 Bath P, Leonardi-Bee J, Bath F. Low molecular weight heparin versus aspirin for acute ischemic stroke: a systematic review. J Stroke Cerebrovasc Dis 2002;11:55-62.
51 Swain $S$, Turner $C$, Tyrrell $P$, et al. Diagnosis and initial management of acute stroke and transient ischaemic attack: summary of NICE guidance. BMJ 2008;337: a786

52 Jauch EC, Saver JL, Adams HP Jr, et al. Guidelines for the early management of patients with acute ischemic stroke: a guideline for healthcare professionals from the American Heart Association/American Stroke Association. Stroke 2013;44:870-947.

53 Alteplase spc. http://www.medicines.org.uk/emc/document.aspx?documentld=308 (accessed Nov 2013)

54 Sharifi M, Bay C, Skrocki L, et al. Moderate pulmonary embolism treated with thrombolysis (from the 'MOPETT' Trial). Am J Cardiol 2013;111:273-7.

55 Wang $C$, Zhai Z, Yang Y, et al. Efficacy and safety of low dose recombinant tissue-type plasminogen activator for the treatment of acute pulmonary thromboembolism: a randomized, multicenter, controlled trial. Chest 2010;137:254-62.

56 McConnell MV, Solomon SD, Rayan ME, et al. Regional right ventricular dysfunction detected by echocardiography in acute pulmonary embolism. Am Cardiol 1996;78:469-73.

57 Kurzyna M, Torbicki $A$, Pruszczyk $P$, et al. Disturbed right ventricular ejection pattern as a new Doppler echocardiographic sign of acute pulmonary embolism. Am J Cardiol 2002:90:507-11.

58 Perrott J, Henneberry RJ, Zed PJ. Thrombolytics for cardiac arrest: case report and systematic review of controlled trials. Ann Pharmacother 2010:44:2007-13.

59 Er F, Nia AM, Gassanov N, et al. Impact of rescue-thrombolysis during cardiopulmonary resuscitation in patients with pulmonary embolism. PLOS ONE 2009;4:e8323.

60 Ruiz-Bailen M, Aguayo-de-Hoyos E, Serrano-Corcoles MC, et al. Thrombolysis with recombinant tissue plasminogen activator during cardiopulmonary resuscitation in fulminant pulmonary embolism. A case series. Resuscitation 2001;51:97-101.

61 British Thoracic Society guidelines for the management of suspected acute pulmonary embolism. Thorax 2003;58:470-83.

62 Kadner A, Schmidli J, Schonhoff $F$, et al. Excellent outcome after surgical treatment of massive pulmonary embolism in critically ill patients. J Thorac Cardiovasc Surg 2008;136:448-51.

63 Bottiger BW, Arntz HR, Chamberlain DA, et al. Thrombolysis during resuscitation for out-of-hospital cardiac arrest. N Engl J Med 2008;359:2651-62.

64 Leacche M, Unic D, Goldhaber SZ, et al. Modern surgical treatment of massive pulmonary embolism: results in 47 consecutive patients after rapid diagnosis and aggressive surgical approach. J Thorac Cardiovasc Surg 2005;129: 1018-23.

65 Todoran TM, Sobieszczyk P. Catheter-based therapies for massive pulmonary embolism. Prog Cardiovasc Dis 2010;52:429-37.

66 Kuo WT, Gould MK, Louie JD, et al. Catheter-directed therapy for the treatment of massive pulmonary embolism: systematic review and meta-analysis of modern techniques. J Vasc Interv Radiol 2009:20:1431-40.

67 Stein PD, Alnas M, Beemath A, et al. Outcome of pulmonary embolectomy. Am J Cardiol 2007:99:421-3.

68 Vohra HA, Whistance RN, Mattam K, et al. Early and late clinical outcomes of pulmonary embolectomy for acute massive pulmonary embolism. Ann Thorac Surg 2011:90:1747-52.

69 Greelish JP, Leacche M, Solenkova NS, et al. Improved midterm outcomes for type A (central) pulmonary emboli treated surgically. J Thorac Cardiovasc Surg 2011;142:1423-9.

70 Aymard T, Kadner A, Widmer A, et al. Massive pulmonary embolism: surgical embolectomy versus thrombolytic therapy — should surgical indications be revisited? Eur J Cardiothorac Surg 2013:43:90-4.

71 Daniels LB, Parker JA, Patel SR, et al. Relation of duration of symptoms with response to thrombolytic therapy in pulmonary embolism. Am J Cardiol 1997:80:184-8.

72 Meneveau N, Seronde MF, Blonde MC, et al. Management of unsuccessful thrombolysis in acute massive pulmonary embolism. Chest 2006;129:1043-50

73 Smulders YM. Pathophysiology and treatment of haemodynamic instability in acute pulmonary embolism: the pivotal role of pulmonary vasoconstriction. Cardiovasc Res 2000:48:23-33.

74 Szold O, Khoury W, Biderman P, et al. Inhaled nitric oxide improves pulmonary functions following massive pulmonary embolism: a report of four patients and review of the literature. Lung 2006;184:1-5.

75 Kline JA, Hernandez J, Garrett JS, et al. Pilot study of a protocol to administer inhaled nitric oxide to treat severe acute submassive pulmonary embolism. Emerg Med J 2013 Published Online First 13 April 2013 doi:10.1136/ emermed-2013-202426

76 Webb SA, Stott S, van Heerden PV. The use of inhaled aerosolized prostacyclin (IAP) in the treatment of pulmonary hypertension secondary to pulmonary embolism. Intensive Care Med 1996;22:353-5.

77 Idrees MM, Batubara E, Kashour T. Novel approach for the management of sub-massive pulmonary embolism. Ann Thorac Med 2012;7:157-61. 
78 Kooter AJ, lizerman RG, Kamp 0, et al. No effect of epoprostenol on right ventricular diameter in patients with acute pulmonary embolism: a randomized controlled trial. BMC Pulm Med 2010 10:18.

79 Galea M, Quiney N. Sildenafil in acute pulmonary embolism: case report and review of literature. J Inten Care Soc 2009;10:44-5.

80 Greer IA, Nelson-Piercy C. Low-molecular-weight heparins for thromboprophylaxis and treatment of venous thromboembolism in pregnancy: a systematic review of safety and efficacy. Blood 2005;106:401-7.

81 Shaul WL, Hall JG. Multiple congenital anomalies associated with oral anticoagulants. Am J Obstet Gynecol 1977;127:191-8.

82 RCOG. The acute management of thrombosis and embolism during pregnancy and the puerperium. http://www.rcog.org.uk/files/rcog-corp/GTG37b_230611.pdf (accessed Nov 2013)

83 Gartman EJ. The use of thrombolytic therapy in pregnancy. Obstet Med 2013;6:105-11.

84 O'Keeffe SA, McGrath A, Ryan JM, et al. Management of a massive pulmonary embolism in a pregnant patient with mechanical fragmentation followed by delayed catheter-directed thrombolysis in the early postpartum period. J Matern Fetal Neonatal Med 2008;21:591-4.

85 Taniguchi S, Fukuda I, Minakawa M, et al. Emergency pulmonary embolectomy during the second trimester of pregnancy: report of a case. Surg Today 2008;38:59-61.

86 Torbicki A, Galie N, Covezzoli A, et al. Right heart thrombi in pulmonary embolism: results from the International Cooperative Pulmonary Embolism Registry. J Am Coll Cardiol 2003:41:2245-51.

87 Chartier L, Bera J, Delomez $M$, et al. Free-floating thrombi in the right heart: diagnosis, management, and prognostic indexes in 38 consecutive patients. Circulation 1999;99:2779-83.

88 Chapoutot L, Nazeyrollas P, Metz D, et al. Floating right heart thrombi and pulmonary embolism: diagnosis, outcome and therapeutic management. Cardiology 1996;87:169-74.

89 Mansencal N, Attias D, Caille V, et al. Computed tomography for the detection of free-floating thrombi in the right heart in acute pulmonary embolism. Eur Radiol $2011: 21: 240-5$

90 Ferrari E, Benhamou M, Berthier F, et al. Mobile thrombi of the right heart in pulmonary embolism: delayed disappearance after thrombolytic treatment. Chest 2005;127:1051-3.

91 European Working Group on Echocardiography. The European Cooperative Study on the clinical significance of right heart thrombi. Eur Heart J 1989;10: 1046-59.

92 Finlayson GN. Right heart thrombi: consider the cause. Can J Cardio/ 2008;24:888.

93 Ruiz-Bailen M, Lopez-Caler C, Castillo-Rivera A, et al. Giant right atrial thrombi treated with thrombolysis. Can J Cardiol 2008:24:312-14.

94 Rose PS, Punjabi NM, Pearse DB. Treatment of right heart thromboemboli. Chest 2002:121:806-14

95 Fauveau E, Cohen A, Bonnet N, et al. Surgical or medical treatment for thrombus straddling the patent foramen ovale: impending paradoxical embolism? Report of four clinical cases and literature review. Arch Cardiovasc Dis 2008;101: 637-44.

96 Decousus $H$, Leizorovicz A, Parent $F$, et al. A clinical trial of vena caval filters in the prevention of pulmonary embolism in patients with proximal deep-vein thrombosis. Prevention du Risque d'Embolie Pulmonaire par Interruption Cave Study Group. N Engl J Med 1998;338:409-15.

97 PREPIC study group. Eight-year follow-up of patients with permanent vena cava filters in the prevention of pulmonary embolism: the PREPIC (Prevention du Risque $\mathrm{d}^{\prime}$ Embolie Pulmonaire par Interruption (ave) randomized study. Circulation 2005;112:416-22.

98 Kucher N, Rossi E, De Rosa M, et al. Massive pulmonary embolism. Circulation 2006;113:577-82

99 Mismetti P, Ennezat PV, Quere I, et al. Prevention of pulmonary embolism recurrences by retrievable vena cava filter: Results of the randomized multicenter trial PREPIC-2. J Thromb Haemost 2013;11:28.

100 Auger WR, Moser KM. Pulmonary flow murmurs; a distinctive physical sign found in chronic pulmonary thromboembolic disease. Clin Res 1989;37:145A.
101 Ribeiro A, Lindmarker $\mathrm{P}$, Johnsson $\mathrm{H}$, et al. Pulmonary embolism: one-year follow-up with echocardiography Doppler and five-year survival analysis. Circulation 1999:99:1325-30.

102 Hasegawa I, Boiselle PM, Hatabu H. Bronchial artery dilatation on MDCT scans of patients with acute pulmonary embolism: comparison with chronic or recurrent pulmonary embolism. Am J Roentgenol 2004;182:67-72.

103 Castaner E, Gallardo X, Rimola J, et al. Congenital and acquired pulmonary artery anomalies in the adult: radiologic overview. Radiographics 2006;26:349-71.

104 Donze J, Le Gal G, et al. Prospective validation of the Pulmonary Embolism Severity Index. A clinical prognostic model for pulmonary embolism. Thromb Haemost 2008;100:943-8.

105 Aujesky D, Roy PM, Verschuren F, et al. Outpatient versus inpatient treatment for patients with acute pulmonary embolism: an international, open-label, randomised, non-inferiority trial. Lancet 2011:378:41-8.

106 Piran S, Le Gal G, Wells PS, et al. Outpatient treatment of symptomatic pulmonary embolism: a systematic review and meta-analysis. Thromb Res 2013;132:515-19.

107 Rudd KM, Phillips EL. New oral anticoagulants in the treatment of pulmonary embolism: efficacy, bleeding risk, and monitoring. Thrombosis 2013 Published Online First 10 April 2013 doi: org/10.1155/2013/973710

108 National Institute for Health and Care Excellence. Rivaroxiban for treating pulmonary embolism and preventing recurrent venous thromboembolism. Technology Appraisal Guidance 287. http://guidance.nice.org.uk/TA287 (accessed Nov 2013).

109 Moores L, Zamarro C, Gomez V, et al. Changes in PESI scores predict mortality in intermediate-risk patients with acute pulmonary embolism. Eur Respir J 2013:41:354-9.

110 Schulman S, Kearon C, Kakkar AK, et al. Dabigatran versus warfarin in the treatment of acute venous thromboembolism. $N$ Engl J Med 2009:361:2342-52.

111 Buller HR, Decousus $H$, Mercuri M, et al. Edoxaban versus warfarin for the treatment of symptomatic venous thromboembolism. $N$ Engl J Med 2013:369:1406-15.

112 Buller HR, Prins MH, Lensin AW, et al. Oral rivaroxaban for the treatment of symptomatic pulmonary embolism. N Engl J Med 2012;366:1287-97.

113 Agnelli G, Buller HR, Cohen A, et al. Oral apixaban for the treatment of acute venous thromboembolism. N Engl J Med 2013;369:799-808.

114 Ritchie G, McGurk S, McCreath C, et al. Prospective evaluation of unsuspected pulmonary embolism on contrast enhanced multidetector CT (MDCT) scanning. Thorax 2007:62:536-40.

115 Gosselin MV, Rubin GD, Leung AN, et al. Unsuspected pulmonary embolism: prospective detection on routine helical CT scans. Radiology 1998;208:209-15.

116 O'Connell CL, Boswell WD, Duddalwar V, et al. Unsuspected pulmonary emboli in cancer patients: clinical correlates and relevance. J Clin Oncol 2006;24:4928-32.

117 Douma RA, Kok MG, Verberne LM, et al. Incidental venous thromboembolism in cancer patients: prevalence and consequence. Thromb Res 2010;125:e306-9.

118 Hui GC, Legasto A, Wittram C. The prevalence of symptomatic and coincidental pulmonary embolism on computed tomography. J Comput Assist Tomogr 2008:32:783-7.

119 den Exter PL, Hooijer J, Dekkers OM, et al. Risk of recurrent venous thromboembolism and mortality in patients with cancer incidentally diagnosed with pulmonary embolism: a comparison with symptomatic patients. J Clin Oncol 2011;29:2405-9.

120 Stein PD, Goodman LR, Hull RD, et al. Diagnosis and management of isolated subsegmental pulmonary embolism: review and assessment of the options. Clin Appl Thromb Hemost 2012;18:20-6.

121 Le Gal G, Righini M, Parent F, et al. Diagnosis and management of subsegmental pulmonary embolism. J Thromb Haemost 2006;4:724-31.

122 Carrier M, Righini M, Wells PS, et al. Subsegmental pulmonary embolism diagnosed by computed tomography: incidence and clinical implications. A systematic review and meta-analysis of the management outcome studies. J Thromb Haemost 2010;8:1716-22.

123 den Exter PL, van Es J, Klok FA, et al. Risk profile and clinical outcome of symptomatic subsegmental acute pulmonary embolism. Blood 2013;122:1144-9. 